\title{
autêntica
}

DOI https://doi.org/10.31639/rbpfp.v13i25.395

ARTIGOS

\section{A RELAÇÃO TEORIA E PRÁTICA NO PROGRAMA RESIDÊNCIA PEDAGÓGICA DA UNIVERSIDADE FEDERAL DO PIAUÍ}

Antonia Dalva FRANÇA - CARVALHO

Universidade Federal do Piaui- UFPI

Teresina-PI

ORCID:https://orcid.org/0000-0002-9827-061X

adalvac@uol.com.br

Raimunda Alves MELO

Universidade Federal do Piaui- UFPI

Teresina-PI

ORCID: https://orcid.org/0000-0003-3652-8213

raimundinhamelo@yahoo.com.br

Luisa Xavier de OLIVEIRA

Universidade Federal do Piauí- UFPI

Teresina-PI

ORCID: ORCID: https://orcid.org/0000-0003-0782-4793

RESUMO: Este artigo discute o design do Programa Residência Pedagógica (PRP) da CAPES desenvolvido na Universidade Federal do Piauí (UFPI), evidenciando os fundamentos que caracterizam essa experiência, metodologias e estratégias utilizadas para a aproximação entre universidade e escolas e qual a concepção de formação docente embasa as ações do referido programa. Realizou-se pesquisa descritiva de abordagem qualitativa utilizando a observação simples e análise documental da legislação que regulamenta/orienta o programa para produção dos dados. Os resultados apontam que a aproximação da IES e as escolas campo acontece principalmente por meio da formação continuada dos professores da educação básica e atuação dos residentes nas diversas atividades desenvolvidas em âmbito escolar. A concepção pedagógica que fundamenta as ações do PRP, a priori, é a perspectiva prática com enfoque reflexivo.

PALAVRAS-CHAVE: Formação inicial de professores. Relação teoria-prática. Reflexividade. 


\title{
THE THEORY AND PRACTICE RELATIONSHIP IN THE PEDAGOGICAL RESIDENCE PROGRAM OF THE FEDERAL UNIVERSITY OF PIAUÍ
}

\begin{abstract}
This research discusses the design of the CAPES Pedagogical Residence Program (PRP) developed at the Federal University of Piauí (UFPI), evidencing the fundamentals that characterize this experience, methodologies and strategies used to approximation universities and schools and what is the conception of teacher training that supports the actions of that program. Descriptive research with a qualitative approach was carried out using simple observation and documentary analysis of the legislation that regulates / guides the program for data production. The results show that the approximation of the IES and the rural schools happens mainly through the continuous training of teachers of basic education and the performance of residents in the various activities developed at school. The pedagogical concept that underlies PRP's actions, a priori, is the practical perspective with a reflective focus.
\end{abstract}

KEYWORDS: Initial teacher training. Theory-practice relationship. Reflexivity.

\section{LA RELACIÓN TEORÍA Y PRÁCTICA EN EL PROGRAMA DE RESIDENCIA PEDAGÓGICA DE LA UNIVERSIDAD FEDERAL DE PIAUÍ}

\begin{abstract}
RESUMEN: Esta investigación analiza el diseño del Programa de Residencia Pedagógica (PRP) CAPES desarrollado en la Universidad Federal de Piauí (UFPI), destacando los fundamentos que caracterizan esta experiencia, las metodologías y estrategias utilizadas para acercar universidades y escuelas y cuál es la concepción de la formación del profesorado sustenta las acciones de ese programa. Se realizó una investigación descriptiva con enfoque cualitativo mediante simple observación y análisis documental de la legislación que regula / orienta el programa de producción de datos. Los resultados muestran que la aproximación de la IES y las escuelas rurales pasa principalmente a través de la formación continua de los docentes de educación básica y el desempeño de los residentes en las diversas actividades desarrolladas en la escuela. El concepto pedagógico que subyace a las acciones de PRP, a priori, es la perspectiva práctica con enfoque reflexivo.
\end{abstract}

PALABRAS CLAVE: Formación inicial del profesorado. Relación teoría-práctica. Reflexividad. 


\section{INTRODUÇÃO}

Nas últimas décadas do Século XX, ampliou-se significativamente o debate sobre a necessidade de melhoria da qualidade da educação básica, bem como o papel da formação de professores para o alcance desse objetivo. Os debates que tratam sobre esta questão encontram respaldo nos resultados de rendimento das escolas públicas brasileiras, que apesar dos avanços, ainda são relativamente baixos. A título de ilustração, dados do Instituto Nacional de Pesquisas (INEP) 1 apontam que a taxa de reprovação escolar e abandono no Ensino Médio, em 2018, foi de 11,5\% e 6,9\%, respectivamente. A distorção de idade-série foi de $31 \%$ e o Índice de Desenvolvimento da Educação da Educação Básica (IDEB) no Brasil de apenas 3,5 em 2017.

Indubitavelmente a mudança desse cenário implica em investir em políticas educacionais para melhorar as condições de trabalho, a infraestrutura escolar, a organização dos currículos, o acompanhamento pedagógico, multiplicar as práticas bem sucedidas de gestão escolar, dentre outros aspectos, assim como a formação de professores.

No que tange as políticas de formação de professores, é importante conhecermos a perspectiva teórica que fundamenta os processos formativos, o perfil docente almejado, assim como conhecimentos e saberes necessários para desenvolver com êxito o seu trabalho. Isso significa que o modelo de ensino e, consequentemente, o modelo de professor assumido pelo sistema de ensino e pela sociedade deve dialogar com os processos formativos, implicando na necessidade de existir uma forte interconexão entre o currículo da formação inicial de professores e o currículo escolar. Assim, os processos formativos devem oferecer experiências por meio das quais os licenciandos possam integrar os conhecimentos pedagógicos e da área de formação ao exercício da prática docente, fazendo relação entre o que se aprende na universidade e o que se desenvolve nas escolas.

Nessa dimensão, o Estágio Curricular Supervisionado é a experiência mais significativa da formação inicial, pois é nele onde se desenvolve a articulação entre teoria e prática indispensável à formação profissional dos professores. Contudo, embora isso seja consensual, na prática, tem se traduzido como um enorme desafio, de modo que as práticas de estágio vêm sendo realizadas, predominantemente, por meio do distanciamento entre os estudos acadêmicos e as ações desenvolvidas nas escolas, tornando este um obstáculo a ser ultrapassado nos cursos de licenciatura.

Foi nesse contexto que o Ministério da Educação (MEC), por meio da Coordenação de Aperfeiçoamento de Pessoal de Nível Superior (CAPES), lançou o Programa Residência Pedagógica (RP), destinado a discentes regularmente matriculados em cursos de licenciatura e desenvolvido numa escola pública de educação básica, denominada escola-campo.. O seu objetivo é aprimorar a formação dos estudantes de cursos de licenciatura, por meio do desenvolvimento de projetos que fortaleçam o campo da prática e conduzam o licenciando a exercitar de forma ativa a relação entre teoria e prática profissional docente (BRASIL, 2018). Sua proposta desafia a implementação de um novo modelo de Estágio Curricular Supervisionado, constituindo-se como uma tentativa de quebra de paradigmas de modelos que tradicionalmente fazem parte do percurso acadêmico dos discentes.

Como parceira institucional no desenvolvimento das ações do Programa Residência Pedagógica, a Universidade Federal do Piauí (UFPI) atendeu no ano de 2018/2019, a 1.020 (Um mil e vinte) estudantes dos cursos de

$1^{5}$ Dados obtidos na Plataforma Qedu, disponível no endereço eletrônico: https://www.qedu.org.br/sobre 
Licenciatura, sendo 816 (oitocentos e dezesseis) bolsistas e 204 (duzentos e quatro) voluntários. Os residentes foram acompanhados por 102 (cento e dois) professores preceptores e 34 (trinta e quatro) docentes orientadores, professores efetivos desta IES.

Na UFPI, a RP foi desenvolvida nos 5 (cinco) campi: Campus Ministro Petrônio Portella (Teresina-PI), Campus Amílcar Ferreira Sobral (Floriano-PI), Campus Helvídio Nunes de Barros (Picos-PI), Campus Professora Cinobelina Elvas (Bom Jesus) e Campus Ministro Reis Velloso, hoje UFDPar. Os cursos contemplados foram: Língua Portuguesa, Arte, Educação Física, Língua Inglesa, Língua Espanhola, Matemática, Ciências, Física, Química, Biologia, Geografia, História, Sociologia e Filosofia, e ainda, os cursos de Pedagogia, Licenciatura Intercultural Indígena e Licenciatura em Educação do Campo.

Este texto, portanto, mostra o design do Programa Residência Pedagógica (PRP) desenvolvido na Universidade Federal do Piauí (UFPI), evidenciando os fundamentos que caracterizam essa experiência, as metodologias e estratégias utilizadas para a aproximação entre Universidade e Escola e a concepção de formação docente que embasa as ações do referido programa. Sua contribuição incide na ampliação dos conhecimentos acerca da formação de professores, evidenciando avanços e desafios, possibilitando aos leitores conhecimentos sobre o Programa Residência Pedagógica no âmbito do Piauí e, especificamente, na UFPI.

\section{METODOLOGIA}

Desenvolveu-se pesquisa descritiva de abordagem qualitativa por meio da qual interpretou-se as ações dos interlocutores a partir da realidade pesquisada. Nessa tipologia de pesquisa, a produção de dados ocorre através de relações que possuem caráter exploratório, em que o investigador estuda o objeto no cenário explorado (MINAYO, 2009). No processo de produção de dados, utilizou-se a observação simples e análise documental. A observação simples por se tratar de uma importante técnica de produção de dados que, segundo Gil (2011) desempenha papel imprescindível na compreensão de um objeto de estudo. Nela o pesquisador utiliza-se dos sentidos, de forma planejada para obter informações necessárias para responder ao problema da pesquisa.

Simultaneamente à observação simples, realizou-se a análise documental da legislação que regulamenta o Programa Residência Pedagógica, incluindo o projeto que a Universidade Federal do Piauí submeteu a Coordenação de Aperfeiçoamento de Pessoal de Nível Superior (Capes) para a implementação do referido programa. O processo de análise documental, baseou-se nas orientações de Richardson (2012), segundo o qual deve se constituir em um estudo rigoroso, realizado em três etapas: a) A pré-análise, através da qual realiza-se a seleção e leitura superficial do material; b) A análise do material onde se desenvolve a codificação, categorização e quantificação das informações, mediante leituras atentas e repetidas dos documentos analisados; c) Tratamento dos resultados em que se realizam as inferências, interpretações dos documentos e seleção de recortes textuais para fundamentar a análise.

Os documentos analisados foram: Edital Capes n 06/2018 que trata sobre chamada pública para apresentação de propostas no âmbito do Programa Residência Pedagógica e o Projeto Institucional do Programa Residência Pedagógica UFPI.

A análise documental se constituiu em um processo complexo através do qual relacionamos os dados coIhidos nos documentos e as sínteses registradas por meio dos processos de observação, contrapondo as orientações documentais e os modos de operacionalização do Programa Residência Pedagógica. 


\section{PROGRAMA RESIDÊNCIA PEDAGÓGICA DA UNIVERSIDADE FEDERAL DO PIAUí}

O PRP foi instituído por meio da Portaria GAB № 38, de 28 de fevereiro de 2018 publicada pela Coordenação de Aperfeiçoamento de Pessoal de Nível Superior (CAPES), com o propósito de induzir, fomentar e acompanhar a formação inicial e continuada de profissionais de magistério, reconhecendo a importância da formação inicial de professores da educação básica para o desenvolvimento humano e sustentável do País (BRASIL, 2018). Sua finalidade é apoiar as Intuições de Ensino Superior (IES) na implementação de projetos inovadores que estimulem a articulação entre teoria e prática nos cursos de licenciatura, conduzidos em parceria com as redes públicas de educação básica. Para tanto, uma das primeiras iniciativas é a apresentação de um projeto pelas IES interessadas em desenvolver as ações do referido programa.

A Universidade Federal do Piauí (UFPI) ao aderir ao pleito teve sua proposta aprovada contemplando 14 subprojetos de componentes curriculares distintos, estruturados em 34 (trinta e quatro) núcleos. Cada núcleo integra um docente orientador (professor do ensino superior com experiência comprovada na área de formação de professores e estágio curricular), três preceptores (professores da escola que ministram a disciplina na área do subprojeto e possuem formação específica na área de atuação), o mínimo de vinte e quatro e o máximo de trinta residentes, sendo admitidos seis participantes sem bolsa. Para ser residente o aluno deve estar regularmente matriculado em curso de licenciatura na área do subprojeto, ter cursado o mínimo de $50 \%$ do curso, declarar ter condições de dedicar 440 horas ao PRP, ou seja, um ano e seis meses comprometendo-se por meio da assinatura de um termo de compromisso.

O Quadro 01 apresenta uma síntese do design do Projeto Institucional do Programa Residência Pedagógica UFPI, indicando as etapas, as atividades e a carga-horária correspondente a cada uma e a periodicidade em que foram desenvolvidas. A sua apresentação, assim como a discussão das informações que o compõe responde ao objetivo de conhecer as metodologias e estratégias que são utilizadas para a aproximação entre Universidade e Escola. 


\section{Quadro o1: Etapas do Programa Residência Pedagógica da UFPI}

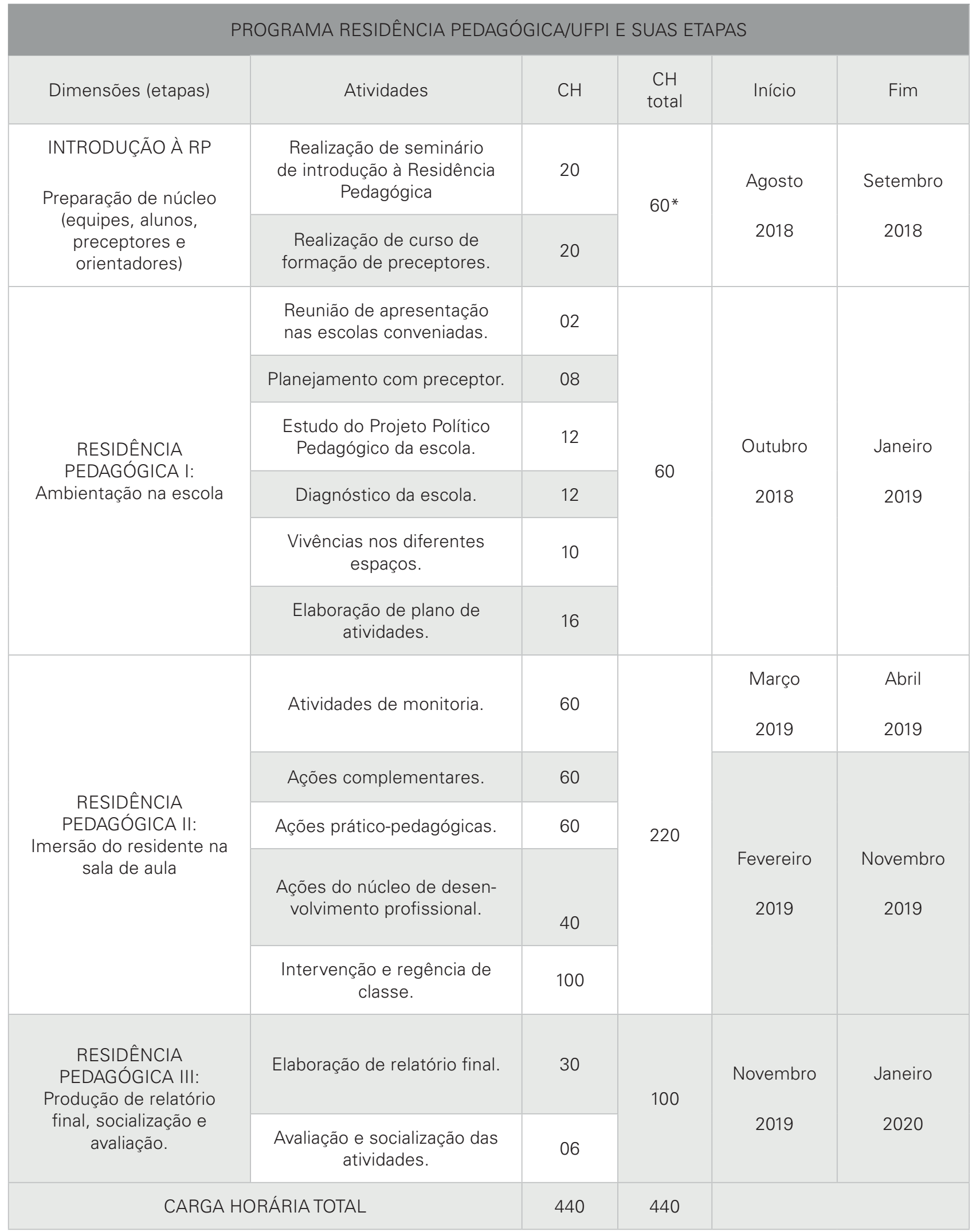


Conforme dados do Quadro 01, o Programa Residência Pedagógica desenvolveu-se a partir de um dinamismo que implicou compromisso e responsabilidade de toda a equipe envolvida, confirmado o que Formosinho (2012) considera acerca da responsabilidade do exercício da docência. Ou seja, requer simultaneamente um desempenho intelectual, técnico, relacional e moral, exigindo dos professores compromisso cívico e com a comunidade escolar. Isso significa que as técnicas didáticas não são condição suficiente para o exercício da docência. Como assevera Grillo (2020), em razão da complexidade da atividade de ensino que envolve questões teóricas e práticas, à docência deve ser estudada sob a ótica de três dimensões. A primeira é a dimensão pessoal que refere-se às direções que o professor imprime ao seu fazer docente. A segunda é dimensão do conhecimento profissional sendo relativa ao conhecimento necessário ao professor para realizar o ensino e constitui-se de diferentes tipos de conhecimentos articulados. E a última dimensão é a contextual que se constitui pela diversidade cultural e a pluralidade tecnológica da sociedade atual, responsáveis pela criação de novos espaços do conhecimento e exigindo uma prática docente aberta para a realidade.

Considerando estes postulados, a identidade do docente define-se no equilíbrio entre as características pessoais e profissionais, razão pela qual os programas de formação de professores, a exemplo do que propõe o PRP, devem contemplar ações e experiências através das quais o futuros profissionais possam obter conhecimentos e desenvolver saberes englobando estes diferentes aspectos destacados por Grillo (2020) e mencionados por Carvalho (2007) .

A primeira etapa do Programa Residência Pedagógica contemplou a formação continuada dos preceptores e residentes, sendo realizada por meio de um Seminário de Introdução ao programa e um curso de iniciação à docência composto por atividades presenciais e à distância. Além dessas duas ações, o Projeto Institucional do PRP da Universidade Federal do Piauí apresenta um eixo de ação denominado de um Núcleo de Desenvolvimento Profissional (NDP) onde são promovidos estudos/reflexões/discussões dos referenciais teóricos contemporâneos educacionais necessários para a compreensão e exercício da docência por meio de encontros formativos semanais em cada subprojeto.

As atividades formativas do PRP objetivaram promover a reflexão sobre a formação docente, construir significado crítico reflexivo da docência, possibilitar suporte o desenvolvimento das ações dos Programa Residência Pedagógica e fomentar aprendizagens significativas de metodologia do ensino e intervenções pedagógicas de aprendizagem dos alunos na escola. O propósito foi ampliar conhecimentos e favorecer a (re)elaboração de saberes docentes, favorecendo o diálogo entre a prática e as teorias que a fundamenta de forma a fomentar a compreensão e aprendizado de intervenção das escolas-campo.

Ao analisar como é concebida e concretizada a aproximação entre Universidade e Escola na formação inicial de professores no PRP desenvolvido pela UNIFESP, Campus Guarulhos, Poladian (2019, p. 3063) afirma que um dos aspectos mais relevantes do programa é "proporcionar a aproximação da formação inicial e continuada, já que as escolas que participam do Programa, como contrapartida, participam de momentos de formação continuada desenvolvidos pelos professores preceptores e pela própria universidade". Ressalta-se que ao desenvolver a formação continuada de professores da educação básica, as IES asseguram que o PRP cumpra um dos de seus objetivos que é contribuir para a melhoria da qualidade da educação básica, a exemplo do que realiza a Universidade Federal do Piauí - UFPI.

Em síntese, por meio da observação simples foi possível perceber que a primeira etapa do Programa Residência Pedagógica foi necessária e relevante para que todos os participantes do PRP pudessem compreender a proposta, adquirir conhecimentos o desenvolvimento das atividades propostas nas etapas seguintes. A 
segunda etapa do PRP desenvolveu-se por meio de atividades de ambientação e imersão dos residentes na escola, através das quais os bolsistas tiveram a oportunidade de conhecer os espaços escolares, o Projeto Político Pedagógico (PPP) da escola e interagir com os diferentes membros da comunidade escolar. O objetivo dessa fase foi situar os estudantes no contexto escolar e suscitando reflexões a partir de três níveis propostos por Garcia (1999), a saber: a) Primeiro nível - através da análise das ações explicitas via observação da prática educativa escolar, dos espaços e do diálogo com os diferentes sujeitos da escola com o propósito de conhecer o ambiente de atuação; b) Segundo nível - reflexões sobre o planejamento escolar observando o propósito com o qual é realizado, como é desenvolvido com destaque para o caráter didático das ações pedagógicas; c) Terceiro nível - reflexões e análise sobre as considerações éticas e políticas da própria prática, contraponto as orientações do Projeto Político Pedagógico da escola e a prática educativa desenvolvida.

Segundo o Projeto Institucional do Programa Residência Pedagógica UFPI, esta etapa do PRP parte do pressuposto de que conhecer bem o cenário escolar, o projeto político pedagógico da instituição e as características dos diferentes membros da comunidade é condição basilar para o sucesso da prática educativa. Sendo o Projeto composto pelo conjunto de diretrizes que direcionam o processo pedagógico intencional da instituição educativa, o estudo crítico e reflexivo desse documento é relevante para o conhecimento das intencionalidades que compõem o planejamento escolar, assim como norteamento das ações que visam contribuir para a solução dos problemas identificados, como lembra Bicudo (2011). Como se trata de um documento onde consta planos de intenções, vislumbrando ações e objetivos que só se concretizam mediante a atuação do grupo a quem se destina, nem sempre o que se encontra disposto nesse documento se materializa de fato na prática educativa.

Ainda nesta etapa os residentes elaboraram um plano de atividades, detalhando as ações, objetivos e estratégias a serem desenvolvidas na escola campo de atuação, considerando os conhecimentos adquiridos nas atividades anteriores. É no momento do planejamento, assim como no exercício da prática docente que os professores têm a oportunidade de evidenciar seu perfil, desmontando o nível de comprometimento, a competência técnica e pedagógica. Nesse sentido, o PRP aponta em direção a um professor afetivo, acoIhedor e receptivo, otimista e entusiasmado, confiante no potencial dos estudantes, conforme demonstrou a análise documental do Projeto Institucional do Programa Residência Pedagógica UFPI.

A terceira etapa do PRP, de imersão na sala de aula, cumprindo uma carga horária de 12 horas semanais. A ações dessa etapa foram distribuídas três eixos: a) Monitoria - caracterizadas pelo atendimento individual e de pequenos grupos de alunos das escolas conveniadas, pelos residentes, para dirimir dúvidas e apoiá-los na aprendizagem durante todo o ano letivo b) Atividades Complementares - caracterizadas pela observação, participação e acompanhamento das atividades de ensino, possibilitando ampliar os conhecimentos sobre os conteúdos das áreas epistemológicas envolvidas no projeto através do desenvolvimento de oficinas, minicursos, palestras, seminários e feiras; c) Atividades de ensino prático-pedagógico - constituem as experiências práticas de docência através das quais os residentes tiveram a oportunidade de preparar materiais didáticos e desenvolver oficinas de aprendizagem com os alunos da educação básica.

A análise das atividades que compõem esta fase inferem que se trata de um programa cujas proposições dialogam com as ponderações de Imbernón (2011), segundo o qual a formação deve constituir-se numa alternativa, possibilidade de criação de espaços de reflexão e partilha onde o licenciando aprenda a conviver com a mudança, com o imprevisível, com a incerteza. Para tanto, os processos formativos valorizam os aspectos atitudinais, possibilitando aos licenciandos vivenciar emoções, melhorar a comunicação com os diferentes membros da comunidade escolar e, principalmente fornecer respostas aos atuais problemas educacionais. 
Ao longo das seções de observação foi possível perceber que a imersão dos residentes dentro da escola-campo se concretizou como uma das ações mais relevantes do Programa Residência Pedagógica, não desmerecendo as outras etapas. Nessa etapa os residentes vivenciaram experiências através das quais formaram conceitos sobre a docência e estabeleceram uma relação mais direta com a escola e os estudantes, reafirmando que "é no confronto com a prática educativa que ocorrem as situações de aprendizagem mais significativas, uma vez que os docentes percebem a relação teoria e prática.", como afirma Formosinho (2009, p. 9). Durante e após a imersão na sala de aula, os residentes foram estimulados a refletir sobre as ações desenvolvidas, bem como fazer os registros das observações e análises em um diário de aula, tendo em vista que a última etapa do programa inclui a produção de relatório final, incluindo a socialização e avaliação da experiência.

Através dos processos observacionais, constatou-se que o PRP proporciona experiências marcantes para os residentes, pois suas ações são desenvolvidas em estreita relação entre a teoria e a prática. É nítido que a dimensão dessa contribuição difere de sujeito para sujeito, pois o desenvolvimento profissional tem uma intima ligação com o fato de cada pessoa compreender a si mesmo como ser humano, como estudante, como profissional. Imbernón (2011), afirma que essa compreensão se desenvolve de acordo com as vivências e ao mesmo tempo que o desenvolvimento cognitivo e teórico, tudo o que o professor vive permite ou impede o desenvolvimento de um certo fim, ou seja, todas as vivências e experiências carregam um caráter importantíssimo para a construção do ser professor.

É relevante ressaltar que ao longo dos 18 (dezoito) meses de execução do Programa Residência Pedagógica houve desafios, entre eles a modificação no âmbito das atuais práticas de estágio desenvolvidas na instituição, a regulamentação do estágio proposto pelo PRP na UFPI, as condições de trabalho em algumas escolas ainda não são suficientes e isso prejudica o desenvolvimento de algumas atividades propostas, e dificuldades relacionadas ao deslocamento de residentes para as escolas mais distantes, entre outras. Contudo, não se constituíram empecilhos para sua execução.

\section{CONCEPÇÃO DE FORMAÇÃO DE PROFESSORES NO PROGRAMA RESIDÊNCIA PEDAGógICA}

Este item contempla discussões sobre os fundamentos e as concepções de formação docente propostas pelo Programa Residência Pedagógica. A sua produção ocorreu por meio da análise documental da legislação que regulamenta o PRP, bem como do Projeto Institucional apresentado pela UFPI. Ao longo das discussões buscou-se relacionar os dados colhidos nos documentos com as sínteses registradas por meio dos processos de observação, já caracterizados no item anterior, contrapondo as orientações documentais e os modos de operacionalização do referido programa.

No cenário das políticas educacionais existe a crença de que a formação de professores se constitui como ação estratégica capaz de promover mudanças nos sistemas de ensino, na concepção dos docentes e na obtenção de êxito no desenvolvimento dos projetos de educação. É por essa razão que desde os anos de 1990, a formação de professores vem ocupando papel de destaque nas políticas educacionais e nos debates acadêmicos.

De fato, historicamente o papel dos professores adquiriu diferentes naturezas de âmbito social, com forte vinculação política e econômica. Assim, ao tratar sobre a formação de professores é necessário refletir e definir o perfil desse profissional e que saberes e conhecimentos ele deve dispor para contribuir para a formação do ser humano com perfil almejado pela sociedade. Nesse panorama, a formação docente é muito 
mais complexa do que transparece ser, razão pela qual é necessário conhecer as diferentes perspectivas que fundamentam as políticas educacionais nessa área.

Nessa direção, García (1999) afirma que diferentes orientações conceituais permeiam o campo das estruturas e racionalidades da formação de professores, sendo que estas concepções variam em função das díspares abordagens e paradigmas norteadores do currículo, da imagem do professor e das perspectivas a respeito dos processos de formação. Elas também definem os processos de seleção, transmissão e produção do conhecimento, a escolha dos métodos e as estratégias utilizadas nos processos de formação.

Embora existam distintas formas para designar as racionalidades que fundamentam as propostas de formação de professores, este estudo fundamentou- se em estudos desenvolvidos por Pérez Gómez (1998, p. 352) que apresentam quatro perspectivas básicas. A acadêmica que defende o caráter eminentemente científico do currículo da formação inicial, compreendido como um processo de transmissão de conhecimentos científicos e culturais, cujo propósito é o domínio do saber científico pelo professor. A técnica que objetiva o desenvolvimento de competências profissionais, tendo em vista que são as competências que viabilizam a aplicação do conhecimento e da técnica. Nesse caso, a formação de professores, realizada por especialistas, prioriza o "treino" dos docentes para o domínio e uso das técnicas. A prática que pode ser caracterizada sob dois enfoques: o tradicional que propõe uma formação baseada em um modelo associado a aprendizagem pela experiência e observação e o enfoque reflexivo que defende uma formação diretamente vinculada à ação reflexiva dos professores sobre a prática, para a prática e a partir da prática. Por fim, a perspectiva da reconstrução social idealiza uma formação que desenvolva a capacidade crítica dos formandos para análise do contexto social que rodeia os processos de ensino e aprendizagem, mas que excedam os muros das escolas, enxergando, criticando, e encabeçando proposições com vistas à superação das contradições sociais.

A análise da caracterização dos processos formativos desenvolvidos no âmbito do Programa Residência Pedagógica da UFPI, evidenciam que as proposições do referido programa dialogam, a priori, com o viés epistemológico da perspectiva prática com enfoque reflexivo, caracterizada por Nóvoa $(2008$, p. 28) como aquela em que a formação de professores assumem uma forte componente prática, centrada na aprendizagem dos alunos e no estudo de casos concretos, tendo como referência o trabalho escolar.

A análise dos objetivos do PRP, dispostos nos documentos analisados, também apontam para esta conclusão. Com o propósito de ilustrar a análise empreendida, destaca-se alguns recortes do Edital 06/2018:

O objeto do presente edital é selecionar, no âmbito do Programa de Residência Pedagógica, Instituições de Ensino Superior (IES) para implementação de projetos inovadores que estimulem articulação entre teoria e prática nos cursos de licenciatura. O Programa de Residência Pedagógica visa: I. Aperfeiçoar a formação dos discentes de cursos de licenciatura, por meio do desenvolvimento de projetos que fortaleçam o campo da prática e conduzam o licenciando a exercitar de forma ativa a relação entre teoria e prática profissional docente. (BRASIL, 2018, p. 1).

Ressalta-se que em todos os documentos analisados, a categoria teoria e prática aparece com muita ênfase, apontando para a crença de que a melhoria da qualidade da educação básica e dos cursos de licenciatura implicam necessariamente na reconfiguração dos currículos desses dois níveis de ensino, bem como da interrelação entre o que se aprende na universidade e o que se desenvolve nas escolas.

Nesse sentido, o Projeto Institucional do PRP da Universidade Federal do Piauí (2018) discorre sobre a articulação teoria e prática como um dos principais princípios que orientam o desenvolvimento em todas as ações do PRP, conforme ilustração abaixo: 
[...] a relação teoria e prática ocorrerá por meio do estudo de conteúdos das áreas de conhecimentos envolvidas do PRP e de sua relação com objetos da BNCC e aplicação por meio das atividades de monitoria, do desenvolvimento das ações complementares, de ambientação nas escolas, através das quais se promove o conhecimento da escola, de seu projeto político-pedagógico. No eixo do Ensino Prático pedagógico é possível ter como descritor da relação teoria-prática a distinção, produção e utilização de recursos tecnológicos e didáticos que desemboca no conhecimento da BNCC, das diretrizes e currículos da escola e da educação básica, bem como de sua organização e a maneira de firmá-lo no tempo e no espaço educacional, ou seja, congregam simultaneamente currículo e didática, significativamente situados. (UFPI, 2018, p. 6-7).

O estudo da Base Nacional Comum Curricular (BNCC) e a sua implementação nas escolas campo aparece como uma das principais preocupações elencadas no projeto, tendo em vista que esse é um dos objetivos do PRP. Para tanto o Projeto Institucional do PRP contempla um conjunto de ações, a saber: realizar estudo aprofundado da BNCC, no âmbito de cada núcleo de residência pedagógica com o propósito de entender as suas proposições e debater formas de implementação da mesma no âmbito escolar; realizar ações formativas e projetos de extensão para aprofundamento de categorias indispensáveis para a implementação da BNCC no âmbito escolar, desenvolver processos formativos sobre as concepções de avaliação e participação nas atividades de revisão dos currículos no âmbito das redes educacionais, entre outras.

Não é o objetivo desse estudo discorrer sobre as diferentes questões teóricas e metodológicas relacionadas a BNCC e a sua implementação, pois estas são complexas e precisam ser analisadas de forma aprofundada. No entanto, não se pode deixar de reconhecer que ao propor a adequação dos currículos e propostas pedagógicas das licenciaturas às adequações da Base, o Programa Residência Pedagógica contribui para o fortalecimento da articulação entre as Instituições de Ensino Superior e as escolas de educação básica e para melhoria da relação teoria e prática. Isso é possível graças aos estudos da BNCC realizados ao longo de toda a execução do PRP no NDP, do desenvolvimento de projetos de didáticos e outras metodologias desenvolvidas com base nas orientações da BNCC, entre outros aspectos.

Em outro trecho, o Edital 06/2018 afirma que o Programa Residência Pedagógica pretende a "imersão planejada e sistemática do aluno de licenciatura em ambiente escolar visando à vivência e experimentação de situações concretas do cotidiano escolar e da sala de aula que depois servirão de objeto de reflexão sobre a articulação entre teoria e prática" (BRASIL, 2018, p.18), apontando para a perspectiva da prática reflexiva, caracterizada por Zeichner (1993), como aquela em que os professores criticam e desenvolvem teorias práticas à medida que refletem sozinhos e em conjunto na ação e sobre ela, acerca do seu ensino e das condições sociais que modelam as suas experiências de ensino. Nesse aspecto, o NDP teve papel relevante ao promover as reuniões semanais de estudo e formação sobre os referenciais teóricos contemporâneos que fundamentam a prática educativa e a formação de professores, necessários para a reflexão e compreensão da docência.

Ao discorrer sobre a caracterização da formação de professores, Nóvoa (2008, p. 28) afirma que esta precisa ser desenvolvida em estreita relação com os contextos de trabalho, abarcando diferentes dimensões da profissão, promovendo a colaboração de modo que os processos formativos passem por "dentro" da profissão, isto é, valorizem "a aquisição de uma cultura profissional, concedendo aos professores mais experientes um papel central na formação dos mais jovens [...]". Essa posição defende a relação teoria e prática como princípio da aprendizagem da docência, colocando os professores veteranos como participantes ativos no processo de formação dos mais jovens. A esse respeito, ressalta-se o papel do professor (preceptor) que orienta o residente em sala de aula, desempenhando papel fundamental na construção da autonomia e postura docente por parte do residente. 
Nesse sentido, o Programa Residência Pedagógica oportuniza que o residente aprenda a docência residente vivenciando a gestão do cotidiano da sala de aula, planejando e executando atividades como elaboração de planos de aula, aplicação de sequências didáticas, projetos de ensino e atividades de avaliação da aprendizagem dos alunos. Estas intervenções pedagógicas são planejadas conjuntamente pelo docente orientador do curso de formação, pelo preceptor e outros participantes da escola e o docente orientador que atua como mentor das atividades oportunizando ao professor preceptor e aos residentes momentos de formação para que possam agir dentro do espaço formal, atendendo as necessidades da escola e dos alunos. Isso implica em dizer que, na medida em que os residentes são formados nesta exata perspectiva, ou seja, não separam os princípios práticos (ético e estético), teóricos e políticos da prática educativa, como meios criar e recriar novas formas de ação docente, o projeto vislumbra a autonomia e emancipação dos futuros professores. Nesse caso, é emancipatório porque privilegia as condições culturais e políticas nas quais são produzidas a prática e seu contexto social, como assevera Carvalho (2007).

\section{CONSIDERAÇÕES FINAIS}

Este estudo pretendeu evidenciar o design do Programa Residência Pedagógica e o modus operandi utilizadas para a aproximação entre Universidade e Escola, ou seja, suas metodologias e estratégias. Também objetivou conhecer os fundamentos e a concepção de formação docente que embasa as ações do referido programa.

As sínteses observacionais, assim como a análise documental apontam que a aproximação da IES e as escolas campo ocorre por meio de um conjunto de ações, entre a quais se destacam: a formação continuada dos professores da educação básica, a atuação dos residentes nas diversas atividades desenvolvidas em âmbito escolar, o apoio no processo de implementação da BNCC, entre outras.

No que se refere à concepção pedagógica, identificou-se que é a perspectiva prática com enfoque reflexivo de caráter emancipatório que fundamenta à priori, os processos formativos. Isso implica em dizer que a proposta de formação desenvolvida assegura a articulação teoria e prática e reflexividade sobre a prática, para a prática e a partir da prática. Ou seja, fomenta a construção de saberes relativos à docência considerando os contextos da escola e da universidade, promovendo aprendizagens significativas.

Portanto, o modelo de formação inicial do Programa Residência Pedagógica da Universidade Federal do Piauí é relevante. E sua proeminência incide na capacidade de vislumbrar a promoção do desenvolvimento, da autoconsciência e da autonomia profissional do futuro professor.

\section{REFERÊNCIAS}

BRASIL. Senado Federal. Projeto de Lei № 227, de 2007. Sobre a "residência educacional a professores da educação básica", de autoria do Senador Marco Maciel. Disponível em: <https://www25.senado.leg.br/web/ atividade/materias/-/materia/130041. Acesso em 11/03/2020.

BICUDO, M. A. V. Análise qualitativo-fenomenológica de projeto pedagógico. In: BICUDO, M. A. V. Pesquisa qualitativa segundo a visão fenomenológica. São Paulo: Cortez, 2011. p. 121-149.

CAPES. Coordenação de Aperfeiçoamento de Pessoal de Nível Superior. Edital 6: Chamada Pública para apresentação de propostas no âmbito do Programa de Residência Pedagógica. 2018. Brasília: Ministério da Educação, 2018. 
CARVALHO, Antonia Dalva França. A racionalidade pedagógica da ação dos formadores de professores: um estudo sobre a epistemologia da prática docente nos cursos de licenciatura da Universidade Federal do Piauí. Tese de Doutorado. Faculdade de Educação. UFC. Fortaleza, 2007.

GRILLO, M. C. Percursos da constituição da docência. In: ENRICONE, D. (Org.). A docência na educação superior: sete olhares. Porto Alegre: Evangraf, 2006. p. 59 - 72. (inserir na ordem alfabética)

FORMOSINHO, J. (Coord.). Formação de professores: aprendizagem profissional e acção docente. Porto: Porto Editora, 2009.

GARCÍA, C. M. Formação de professores: para uma mudança educativa. Porto: Porto Editora, 1999.

IMBERNÓN, F. Formação docente e profissional: formar-se para a mudança e a incerteza. $9^{a}$ ed. São Paulo. Cortez, 2011.

MINAYO, M. C. de S. O desafio do conhecimento: pesquisa qualitativa em saúde. Rio de Janeiro: Abrasco; São Paulo: Hucitec, 2009.

NÓVOA, A. O regresso dos professores. Lisboa: Ministério da Educação, 2008.

PEREIRA, J. E. D. As licenciaturas e as novas políticas educacionais para a formação docente. In: Educação \& Sociedade: Revista Quadrimestral de Ciências da Educação. Formação de Profissionais da Educação Políticas e Tendências. Campinas: Cedes, nº 68, 1999, p. 109-125.

PÉREZ GÓMEZ, A. I. Ensino para a compreensão. In: SACRISTAN, J. G.; PÉREZ GÓMEZ, A. I. Compreender e transformar o ensino. Porto Alegre: Artmed, 2000.

POLADIAN. M. L. P. Estudo sobre o Programa de Residência Pedagógica da UNIFESP: uma aproximação entre universidade e escola. EdUCERE Livro 2: Didática e Prática de Ensino na relação com a Formação de Professores. Disponível em: http://www.uece.br/endipe2014/ebooks/livro2/ESTUDO\%20SOBRE\%20 O\%20PROGRAMA\%20DE\%20RESID\%C3\%8ANCIA\%20PEDAG\%C3\%93GICA\%20DA\%20UNIFESP\% 20 UMA\%20APROXIMA\%C3\%87\%C3\% 830\%20ENTRE\%20UNIVERSIDADE\%20E\%20ESCOLA.pdf. Acesso em: 11/09/2020.

RICHARDSON, R. J. Pesquisa social: métodos e técnicas. São Paulo: Atlas, 2012.

UNIVERSIDADE FEDERAL DO PIAUÍ. Projeto Institucional do Programa Residência Pedagógica. 2018. Teresina, 2018.

ZEICHNER, K. M. A Formação Reflexiva de Professores: Ideias e Práticas. - Educa. Professores, 1993.

SOUZA, E. K.; DORNELES, B. V.; FRANCO, S. R. K.; Formação continuada de professores: reflexões sobre o desenvolvimento do raciocínio multiplicativo no ciclo de alfabetização Formação Docente - Revista Brasileira de Pesquisa sobre Formação de Professores. Belo Horizonte. Vol. 13, nº 25 (p. 123-136) 31 dez. 2020. ISSN:2176-4360. DOI https://doi.org/10.31639/rbpfp.v13i25.395 
